\title{
Growth and Photomorphogenesis of Pepper Plants under Red Light-emitting Diodes with Supplemental Blue or Far-red Lighting
}

\author{
Christopher S. Brown ${ }^{1}$ \\ Dynamac Corporation, Mail Code DYN-3, Kennedy Space Center, FL 32899 \\ Andrew C. Schuerger \\ Walt Disney World Co., The Land, Epcot, P.O. Box 10,000, Luke Buena Vista, FL 32830
}

John C. Sager

NASA Biomedical Operations and Research Office, Mail Code MD-RES, Kennedy Space Center, FL 32899

Additional index words. Capsicum annuum, Solanaceae, spectral quality, LED, phytochrome

\begin{abstract}
Light-emitting diodes (LEDs) are a potential irradiation source for intensive plant culture systems and photobiological research. They have small size, low mass, a long functional life, and narrow spectral output. In this study, we measured the growth and dry matter partitioning of 'Hungarian Wax' pepper (Capsicum annum L.) plants grown under red LEDs compared with similar plants grown under red LEDs with supplemental blue or far-red radiation or under broad spectrum metal halide (MH) lamps. Additionally, we describe the thermal and spectra1 characteristics of these sources. The LEDs used in this study had a narrow bandwidth at half peak height $(25 \mathrm{~nm})$ and a focused maximum spectral output at $660 \mathrm{~nm}$ for the red and $735 \mathrm{~nm}$ for the far-red. Near infrared radiation (800 to $3000 \mathrm{~nm}$ ) was below detection and thermal infrared radiation $(3000$ to $50,000 \mathrm{~nm})$ was lower in the LEDs compared to the MH source. Although the red to far-red ratio varied considerably, the calculated phytochrome photostationary state $(\phi)$ was only slightly different between the radiation sources. Plant biomass was reduced when peppers were grown under red LEDs in the absence of blue wavelengths compared to plants grown under supplemental blue fluorescent lamps or MH lamps. The addition of far-red radiation resulted in taller plants with greater stem mass than red LEDs alone. There were fewer leaves under red or red plus far-red radiation than with lamps producing blue wavelengths. These results indicate that red LEDs may be suitable, in proper combination with other wavelengths of light, for the culture of plants in tightly controlled environments such as space-based plant culture systems.
\end{abstract}

Spectral quality can have profound effects on the growth, development, and physiology of plants (Sage, 1992; Smith, 1982). The effects of red and far-red radiation on plant growth and development constitute much of the focus of past and current research (Britz and Sager, 1990; McMahon et al., 1991; Rajapaske et al., 1992). Radiation in the blue region of the spectrum is also of critical importance to plant growth and morphology (Barnes and Bugbee, 1992; Senger, 1984; Wheeler et al., 1991).

Because of their small mass, volume, solid state construction and long life, light emitting diodes (LEDs) hold promise as a radiation source for intensive plant culture systems, such as spacebased research chambers or bioregenerative life support systems (Barta et al., 1992; Bula et al., 1991; Hoenecke et al., 1992; Schuerger and Brown, 1994). Due to their wavelength specificity and narrow bandwidth, LEDs also have been usedrecently in many areas of photobiological research. To date, LEDs have been used for studies on chlorophyll biosynthesis in wheat (Tripathy and

Received for publication 5 Jan. 1995. Accepted for publication 4 Mar. 1995. This work was supported by National Aeronuatics and Space Administration contract NAS10-11624 with The Bionetic Corp and contract NAS10-12180 with Dynamac Corp. We thank Kellie McKeown, Mark Turner, and Peter Hadeland for the LED arrays used in this study. We also thank Raymond $\mathrm{M}$. Wheeler for his help and advice, Baishnab C. Tripathy for his critical reading of the manuscript and Neil C. Yorio for assistance with the spectral scans. Mention of a trademark or proprietary product does not constitute a guarantee or warranty by Dynamac Corp., The Bionetics Corp., the Walt Disney World Co., or NASA. Quantum Devices, Barnveld, Wis., holds a patent (no. 5,012,609) on light-emiting diodes as an illumination source for plant growth. The cost of publishing this paper was defrayed in part by the payment of page charges. Under postal regulations, this paper therefore must be hereby marked advertisement solely to indicate this fact.

${ }^{1}$ To whom reprint requests should be addressed.
Brown, 1995), stem elongation and leaf expansion in lettuce (Hoenecke et al., 1992), disease development in pepper and cucumber (Schuerger and Brown, 1994), and photosynthesis research with kudzu (Tennessen et al., 1994).

Several plant species have been successfully cultured under LEDs, including lettuce (Brown and Schuerger, 1993; Bula et al., 1991; Hoenecke et al., 1992), pepper, cucumber (Schuerger and Brown, 1994) and tomato (unpublished data). LEDs can support wheat growth throughout an entire life cycle (Barta et al., 1991; C. Brown, unpublisheddata). However, terrestrial plants have evolved under a wide spectrum of light. Therefore, it is of critical importance to determine if red LEDs alone or combined with other wavelengths or sources of light can support the normal growth and development of plants.

The objective of this study was to quantify the growth and dry matter partitioning of pepper plants grown under a narrow bandwidth red LED light source compared to plants grown under red LEDs supplemented with blue or far-red light, or under a broad spectrum metal halide light source. We also describe the spectral and thermal characteristics of these radiation sources in relation to the growth of the plants. These types of studies are important for understanding plant responses to artificial lighting systems in tightly controlled plant growth systems and the use of LEDs as a radiation source for plant research and biotechnology.

\section{Materials and Methods}

Plant material and cultural conditions. Seeds of 'Hungarian Wax' pepper (Capsicum annuиm) were germinated and seedlings were grown under 400-W metal halide (MH) lamps (ETAC-400- 
MH-CH, Energy Technics, York, Pa.) at $250 \mu \mathrm{mol} \cdot \mathrm{m}^{-2} \cdot \mathrm{s}^{-1}$ photosynthetic photon flux (PPF) for 21 days. Seedlings were transplanted into polypropylene tanks containing 4 liters of hydroponic nutrient solution (Schuerger and Mitchell, 1992) and placed under the MH lamp or three types of LED arrays all set at 300 $\mu \mathrm{mol} \cdot \mathrm{m}^{-2} \cdot \mathrm{s}^{-1} \mathrm{PPF}$ with a 12 -h photoperiod. PPF was maintained at this level by adjusting the distance to the top of the plants relative to the light source. PPF was measured at the top of the plants using a quantum sensor (LI-189; LI-COR, Lincoln, Neb.). One array supplied red light at $660 \mathrm{~nm}$ (660) using red LEDs (3009A001; Quantum Devices, Barnveld, Wis.), another supplied red and farred light at 660 and $735 \mathrm{~nm}(660 / 735)$ using red supplemented with far-red LEDs (3009A002, Quantum Devices Inc.) and the third supplied red light at $660 \mathrm{~nm}$ from red LEDs supplemented with blue light (660/BF) from blue fluorescent lamps (BF6 165-12; JKL Components Corp., Paccoima, Calif.). The LED arrays contained 1344 LED units mounted in a $0.42-\mathrm{m}^{2}$ ventilated enclosure. The MH lamp was housed in a luminaire above a $3 \mathrm{~cm}$ deep, open deionized water barrier supported by a 6.3 -mm-thick tempered glass plate. The water temperature was maintained at $25 \mathrm{C}$ by recirculation through a water chiller (Lauda RMS-20; Brinkmann Instruments, Westbury, N.Y.). The nutrient solution was continuously aerated and $\mathrm{pH}$ was adjusted daily to 5.5 with $0.02 \mathrm{~N} \mathrm{HNO}_{3}$ or $0.02 \mathrm{~N} \mathrm{KOH}$. The electrical conductivity of the nutrient solution was $1700 \mu \mathrm{S} \cdot \mathrm{cm}^{-1}$. Fresh nutrient solution was added daily to replenish evapotranspirative loss. Temperature was maintained at 23 to $26 \mathrm{C}$ for the aerial environment and 21 to $23 \mathrm{C}$ for the root zone environment. Relative humidity remained between $50 \%$ to $65 \%$ throughout the experiment.

Source characteristic measurements. Spectral scans from 300 to $1100 \mathrm{~nm}$ were taken (at equal PPF) with a spectroradiometer (LI-1800; LI-COR). Energy and photon flux integrals were derived from this data. Radiation measurements from 800 to $3000 \mathrm{~nm}$ (near infrared) were made with a PSP pyranometer (The Eppley Laboratory, Newport, R.I.) with a Schott cut-on filter at $805 \mathrm{~nm}$. Radiation from 3000 to $50,000 \mathrm{~nm}$ (thermal infrared) was made with an Eppley PIR pyrgeometer with a silicon cut-on filter at 3000 nm.

Plant growth measurements. Plant growth and morphogenesis were compared. The number of leaves and the length of stems were determined at 7, 14, and 21 days after transfer into the different light treatments. At 21 days after transfer, plants were harvested for measurements of leaf, stem and root dry mass, leaf DM/area and total leaf area.

The experiment was conducted four times with three replicate plants per repetition of the experiment $(n=12)$. Statistical analyses were conducted with the Statistical Analysis System (SAS Institute, Cary, N.C.). Plant growth data were subjected to analysis of variance followed by protected Fisher's least-squares mean separation tests $(P \leq 0.05)$.

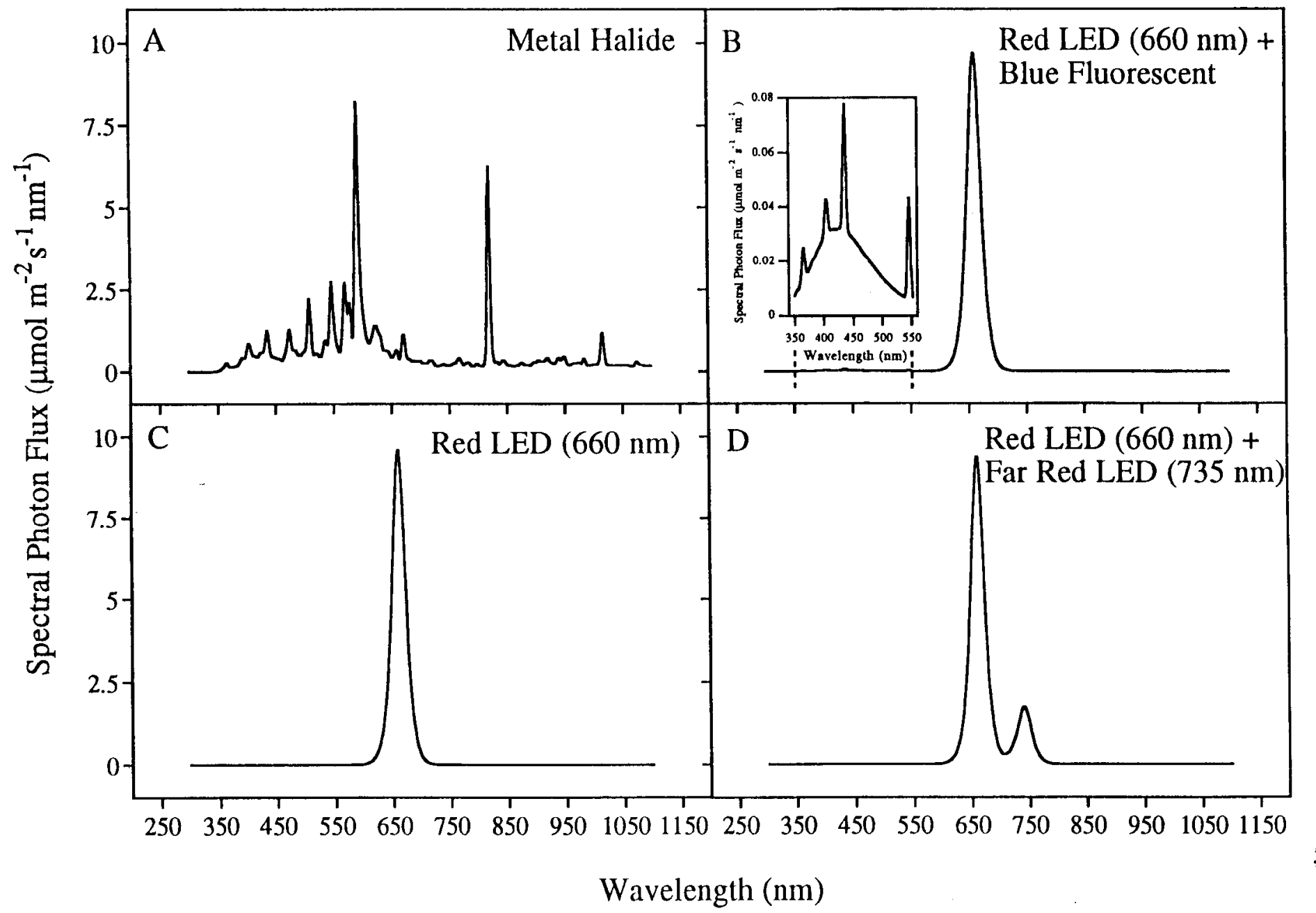

Fig. 1. Spectral distribution of light from metal halide (A), red light-emiting diodes (LEDs) plus blue fluorescent lamps (B), red LEDs (C), and red plus far-red LEDs (D). Spectral scans were recorded with a spectroradiometer. 


\section{Results}

Source characteristics. The LEDs used in this study had narrow spectral outputs ( $25 \mathrm{~nm}$ band width at half peak height) and the photon flux in each waveband was distinct for each of the three arrays (Fig. 1). The narrowly distributed spectra of the LEDs were in contrast to the broad spectrum $\mathrm{MH}$ lamps used as the control source (Fig. 1A). The MH lamps had $20 \%$ of the PPF at 400 to 500 $\mathrm{nm}, 56 \%$ at 500 to $600 \mathrm{~nm}$, and $24 \%$ at 600 to $700 \mathrm{~nm}$. The $660 / \mathrm{BF}$ array supplied $99 \%$ of the total PPF between 600 and $700 \mathrm{~nm}$ and was centered at $660 \mathrm{~nm}$ (Fig. 1B). The blue fluorescent lamps supplied $1 \%$ of the total PPF $\left(3 / 314 \mu \mathrm{mol} \cdot \mathrm{m}^{-2} \cdot \mathrm{s}^{-1}\right)$ in the blue region of the spectrum (400 to $500 \mathrm{~nm}$ ). The 660 array supplied $99.5 \%$ of the PAR between 600 and $700 \mathrm{~nm}$ and was centered at $660 \mathrm{~nm}$ (Fig. 1C). The 660/735 array supplied all of the PPF between 600 and $700 \mathrm{~nm}$ (centered at $660 \mathrm{~nm})$ and had $10 \mathrm{~W} \mathrm{~m}-2\left(59 \mu \mathrm{mol} \cdot \mathrm{m}^{-2} \cdot \mathrm{s}^{-1}\right)$ between 700 and 800, which was centered at $735 \mathrm{~nm}$ (Fig. 1D). The ratio of PPF to total irradiance $\left(\mu \mathrm{mol} \cdot \mathrm{m}^{-2} \cdot \mathrm{s}^{-1} / \mathrm{W} \cdot \mathrm{m}^{-2}\right)$ at 400 to 700 $\mathrm{nm}$ ) was higher for all LED arrays (5.5) compared to the MH lamps (4.6), which indicates a source with a high proportion of red irradiation.

It was necessary to use the water barrier ( 1 to $2 \mathrm{C}$ cooler than ambient air temperature) with the $\mathrm{MH}$ lamps to maintain the aerial temperature around the plants. The spectral data (Table 1) show that the contribution of the MH lamps in the near-infrared (800 to $3000 \mathrm{~nm}$ ), even with the cooled water barrier, is higher than the LED sources. The water barrier actually acted as a radiation sink and reduced the thermal infrared (3000 to $50,000 \mathrm{~nm}$ ) to -8 $\mathrm{W} \cdot \mathrm{m}^{-2}$. Without the water barrier, the thermal radiation was 56 $\mathrm{W} \cdot \mathrm{m}^{-2}$. The higher thermal contribution of the $660 / \mathrm{BF}$ source compared to the other lamp treatments was attributed to the warmer fluorescent lamps in that array. The yield photon flux (YPF), the weighted photosynthetic value of all photons from 360 to $760 \mathrm{~nm}$ (Sager et al., 1988), and the photosynthetic photon flux (PPF, 400 to $700 \mathrm{~nm}$ ) are shown for each array and the MH lamps. The lower relative weighting of the blue (400 to $500 \mathrm{~nm}$ ) and green (500 to $600 \mathrm{~nm}$ ) reduced the YPF relative to the PPF for the MH lamp (Table 1 and Barnes et al. 1993). The phytochrome photostationary state $(\phi)$, calculated according to Sager et al. (1988), showed no marked difference between the radiation sources. The red to far-red ratio (R:FR) of the $\mathrm{MH}$ and 660/735 sources were 3.0 and 5.0, respectively, whereas the LED arrays without a far-red component had R:FR values $>100$.

Plant growth characteristics. At the time of seedling transfer (21 days after planting) to the light treatments, the plants were 6 to $8 \mathrm{~cm}$ long and had two to four partially expanded true leaves. Pepper plants that remained under $\mathrm{MH}$ illumination had significantly greater biomass than plants transferred and grown under any of the LED arrays (Fig. 2). Plants grown under 660 or $660 / 735$ had significantly lower leaf, root, and whole-plant dry mass than the 660/BF-grown plants, which in turn were lower than the $\mathrm{MH}$ grown plants. The mean stem dry mass of the 660-grown plants was significantly less than from any other treatment.

The 660/735-grown plants partitioned more dry mass into stem tissue than plants from the other light treatments, resulting in a significantly lower leaf/stem dry mass ratio (Table 2). Due to the differences in root and leaf dry weights as a result of the light treatments, the increased partitioning into stem tissue did not result in a pronounced difference in shoot/root ratio, although the 660/ 735 plants showed a significantly greater shoot/root ratio than the MH plants (Table 2). Leaf DM/area $\left(\mathrm{g} \cdot \mathrm{m}^{-2}\right)$ of photosynthetically competent leaves was greater in $\mathrm{MH}$ plants than in the LED-grown plants. The $660 / \mathrm{BF}$ plants had a lower leaf DM/area for photosynthetically active leaves than the $\mathrm{MH}$ plants but were significantly greater than the 660 or $660 / 735$ plants. Compared to the 660 -grown plants, blue light in the $660 / \mathrm{BF}$ treatment resulted in a significant increase of $26 \%$ in total leaf area. The whole-plant dry/fresh mass ratio was significantly greater in the $\mathrm{MH}$ plants than the $660 / \mathrm{BF}$ or $660 / 735$ plants. The 660 plants had the lowest dry/fresh mass ratio.

The number of leaves per plant was not different between light treatments until 21 days after transfer (Fig. 3A). At that time, the plants that received blue light (either $\mathrm{MH}$ or $660 / \mathrm{BF}$ ) had significantly more leaves than the plants that were grown under red or red plus far-red light. Differences in stem length were evident as early

Table 1. Spectral data for metal halide (MH), red light-emiting diodes (LEDs) plus blue fluorescent (660/BF), red LEDs (660), and red plus far-red LEDs (660/735). Measurements were taken at the top of the plant canopy with a spectroradiometer.

\begin{tabular}{|c|c|c|c|c|}
\hline \multirow[b]{2}{*}{ Characteristic } & \multicolumn{4}{|c|}{ Lamp } \\
\hline & MH & $660 / \mathrm{BF}$ & 660 & $660 / 735$ \\
\hline \multicolumn{5}{|c|}{ Irradiance $\left(W \cdot m^{-2}\right)$} \\
\hline \multicolumn{5}{|l|}{ Wavelength range $(\mathrm{nm})$} \\
\hline $400-700$ & 69 & 57 & 54 & 53 \\
\hline $300-800$ & 77 & 58 & 54 & 63 \\
\hline $800-3000$ & 13 & 1 & 0 & 4 \\
\hline $3000-50000$ & -8 & 50 & 38 & 35 \\
\hline \multicolumn{5}{|c|}{ Photon flux $\left(\mu \mathrm{mol} \cdot \mathrm{m}^{-2} \cdot \mathrm{s}^{-1}\right)$} \\
\hline $300-400$ & 11 & 1 & 0 & 0 \\
\hline $400-500$ & 63 & 3 & 0 & 0 \\
\hline $500-600$ & 180 & 1 & 0 & 0 \\
\hline $600-700$ & 75 & 310 & 296 & 293 \\
\hline $700-800$ & 25 & 3 & 2 & 59 \\
\hline $400-700(\mathrm{PPF})$ & 318 & 314 & 296 & 293 \\
\hline $300-800$ & 354 & 318 & 298 & 352 \\
\hline Yield photon flux (YPF) & 280 & 289 & 275 & 273 \\
\hline YPF : PPF & 0.88 & 0.92 & 0.93 & 0.93 \\
\hline Phytochrome photostationary state $(\phi)^{2}$ & 0.82 & 0.88 & 0.88 & 0.84 \\
\hline $\mathbf{R}: \mathbf{F R}^{\mathbf{y}}$ & 3.0 & 103.0 & 148.0 & 5.0 \\
\hline
\end{tabular}

${ }^{2}$ Calculated according to Sager et al. (1988).

${ }^{\mathrm{r}} \mathrm{R}=600$ to $700 \mathrm{~nm}: \mathrm{FR}=700$ to $800 \mathrm{~nm}$ (Mortensen and Stromme, 1987; Rajapaske et al., 1992). 


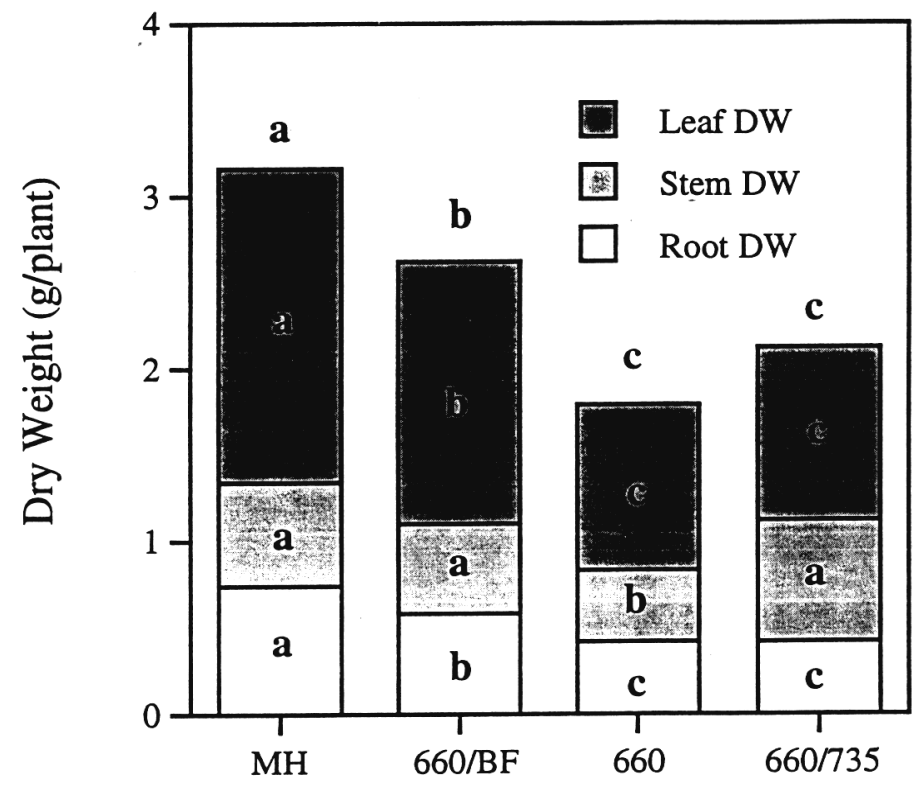

Lamp Type

Fig. 2. Dry weight of leaves, stems, and roots of 42-day-old pepper plants grown for 21 days under metal halide (MH) lamps then transplanted under red lightemiting diodes (LEDs) plus blue fluorescent lamps (660/BF), red LEDs (660), and red plus far-red LEDs (660/735), or maintained under MH lamps for an additional 21 days. Similarly shaded portions containing different letters are significantly different based on ANOVA and protected least-squares mean separation tests $(P \leq 0.05)$. The letters above the bars indicates the significance for the combined plant dry weight.

as 7 days after transfer and became progressively greater (Fig. 3B). At 21 days after transfer, the 660/735-grown plants were 90\% taller than the MH control plants. The 660- and 660/BF-grown plants were $32 \%$ and $19 \%$ taller, respectively, than the $\mathrm{MH}$ control plants.

\section{Discussion}

Red LEDs have been proposed for short- or long-term plant culture (Barta et al., 1992; Bula et al., 1991). Results of the present study support this and indicate that LEDs alone or combined with other sources may be used in controlled-environment plant-growth systems, but the spectral effects on plant growth and development must be carefully examined. This study demonstrates the versatility of LEDs for photosynthetic and photobiological research due to their specific spectral output and potentially high PPF output. Red LEDs, with output at $660 \mathrm{~nm}$ (such as used in this study) supply wavelengths that correspond to the maximum absorbance of chlorophyll (McCree, 1972). In other words, although the electrical efficiency of LEDs is similar to, or less than, conventional lamps for plant growth (M. Turner, personal communication), all the spectral output is potentially useful to drive photosynthesis. With LEDs, this is coupled with a low amount of IR radiation, i.e., heat load on the plant canopy. This is particularly important as it removes the need for barriers between the radiation source and the plants, which can attenuate the PPF reaching the leaf surface. They also offer the advantage of many combinations of red and far-red light. The important blue light component can be added using LED technology with the recent development of high-output blue LEDs. This technology should be suitable as a light source in a plant production system, particularly considering the long lifetime of LEDs compared to conventional arc discharge or incandescent lamps (Barta et al., 1992). However, plant responses to the relatively narrow-band output of LED-tailored spectra are not clear. For example, it has been shown that quantum sensors underestimate PPF delivered from red LEDs compared to MH lamps (Barnes et al., 1993). In the present study, we maintained equivalent PPF levels (as measured with the quantum sensor). If this were an underestimate of the actual PPF, then the expectation might be increased biomass in the red LED-grown plants relative to the $\mathrm{MH}$ grown plants due to greater actual light intensity to drive photosynthesis. However, plants grown in the 660 treatment had lower overall dry mass than the MH control plants. This could be due to a lower relative $\mathrm{CO}_{2}$ assimilation rate of leaves grown under red LEDs (unpublished data).

Past studies have examined the role of far-red and blue light in a broad spectral background on plant development (Barnes and Bugbee, 1992; Britz and Sager, 1990; Hoenecke et al., 1992; McMahon et al., 1992; Rajapaske et al., 1992, 1993; Tibbitts et al., 1983; Wheeler et al., 1991). These studies used sources with different relative amounts of far-red and blue light as the experimental treatment. The present study using LEDs allows us to examine spectral sources with and without precisely defined amounts of supplemental blue or far-red light. Our results show that pepper plants grown under red LEDs require supplemental radiation, especially in the blue region of the spectrum, for normal growth and development. Plants grown under the 660 or 6601735 treatments were similar in some respects to plants grown under red-biased light sources such as high- or low-pressure sodium lamps (Britz and Sager, 1990; Warrington and Mitchell, 1976). For example, plants in this study under LED radiation had longer stems, increased shoot/root ratio (particularly in the 6601735 treatment) and lower leaf dry matter (DM)/area. Only a very low

Table 2. Growth parameters of 42-day-old pepper plants grown for 21 days under metal halide (MH) lamps then transplanted under red light-emiting diodes (LEDs) plus blue fluorescent lamps (660/BF), red LEDs (660), and red plus far-red LEDs (660/735) or maintained under MH lamps for an additional 21 days. Data represent the mean of 12 plants for each light treatment.

\begin{tabular}{lcccr}
\hline \hline & \multicolumn{3}{c}{ Lamp } \\
\cline { 2 - 5 } Growth parameter & $\mathrm{MH}$ & $660 / \mathrm{BF}$ & 660 & $660 / 735$ \\
\hline Leaf/stem $\left(\mathrm{DM}^{\mathrm{z}}\right)$ & $3.0 \mathrm{a}^{\mathrm{y}}$ & $3.0 \mathrm{a}$ & $2.3 \mathrm{~b}$ & $1.5 \mathrm{c}$ \\
Shoot/root $(\mathrm{DM})$ & $3.4 \mathrm{~b}$ & $3.7 \mathrm{ab}$ & $3.6 \mathrm{ab}$ & $4.1 \mathrm{a}$ \\
Leaf DM/area $\left(\mathrm{g}^{-2}\right)^{\mathrm{x}}$ & $20 \mathrm{a}$ & $13 \mathrm{~b}$ & $10 \mathrm{c}$ & $11 \mathrm{c}$ \\
Total leaf area $\left(\mathrm{cm}^{2}\right)$ & $689 \mathrm{ab}$ & $778 \mathrm{a}$ & $573 \mathrm{~b}$ & $532 \mathrm{~b}$ \\
Plant DM/FM $(\%)$ & $8.1 \mathrm{a}$ & $7.5 \mathrm{~b}$ & $6.8 \mathrm{c}$ & $7.3 \mathrm{~b}$
\end{tabular}

${ }^{\mathrm{DM}}=$ dry matter.

'Within a row, values with different letters are significantly different at $P \leq 0.05, \mathrm{n}=12$.

${ }^{x} \mathrm{DM}$ of the first fully expanded leaf. 


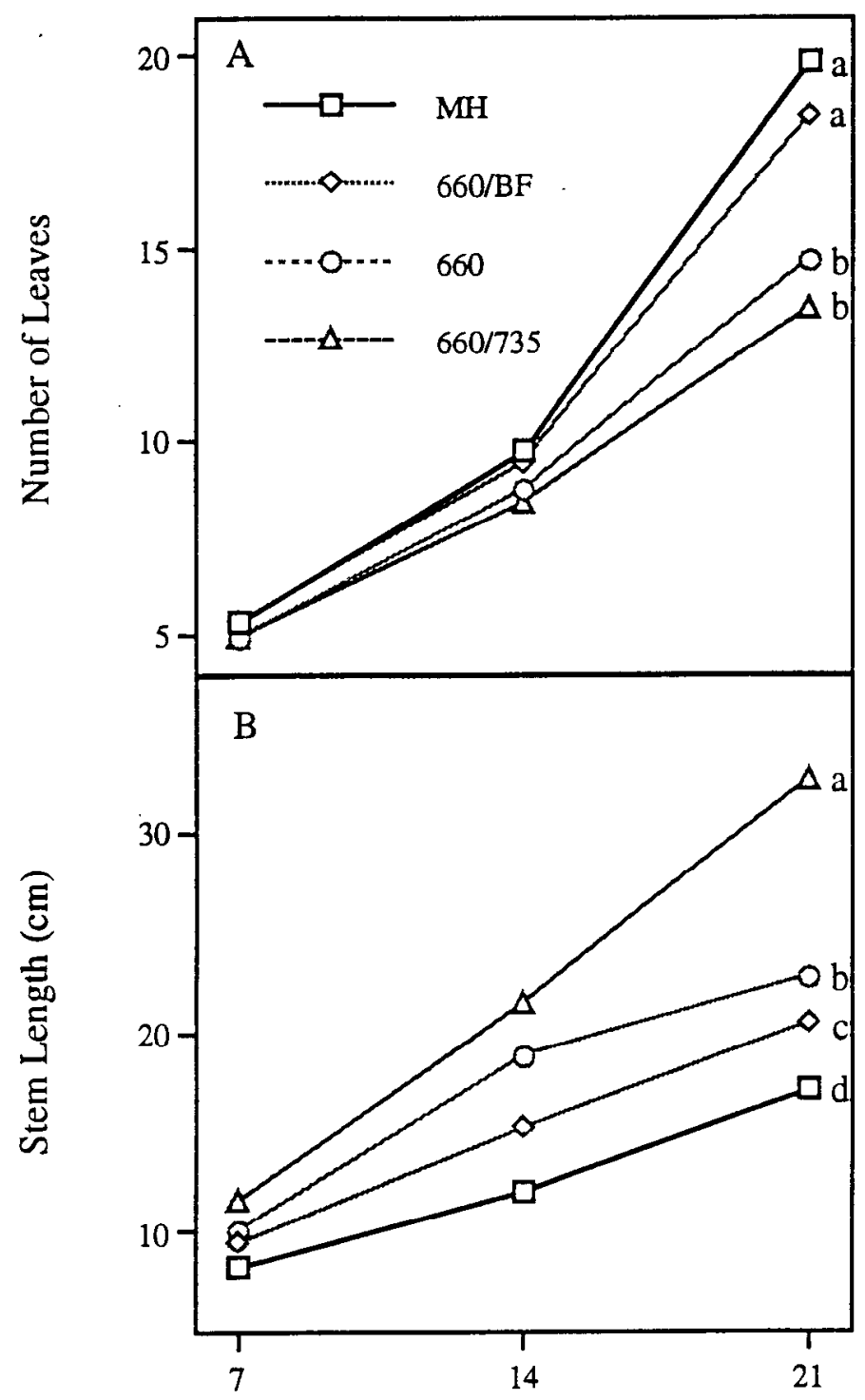

Days After Transfer

Fig. 3. Number of leaves (A) and stem length (B) of 42-day-old pepper plants grown for 21 days under metal halide (MH) lamps then transplanted under red lightemiting diodes (LEDs) plus blue fluorescent lamps (660/BF), red LEDs (660), and red plus far-red LEDs (660/735), or maintained under MH lamps for an additional 21 days. Data points followed by different letters are significantly different based on ANOVA and protected least-squares mean separation tests $(P$ $\leq 0.05)$.

amount of supplemental blue radiation $\left(3 \mu \mathrm{mol} \cdot \mathrm{m}^{-2} \cdot \mathrm{s}^{-1}\right.$ or $1 \%$ of the total PPF) was necessary for the number of leaves and leaf/stem dry mass ratio to be equal to the plants grown under the broadspectrum MH lamps $\left(63 \mu \mathrm{mol} \cdot \mathrm{m}^{-2} \cdot \mathrm{s}^{-1}\right.$ or $21 \%$ of the total PPF as blue). The $660 / \mathrm{BF}$ treatment resulted in greater total plant leaf area (12\% greater) than the $\mathrm{MH}$-grown plants. This agrees with Britz and Sager (1990), who found that leaf area was lower in soybean plants grown under daylight fluorescent lamps, which are rich in blue light compared to low-pressure sodium lamps, which have low but measurable amounts of blue light. The small amount of blue light in the 660/BF treatment partially mitigated the adverse impact of red light in other measured parameters of growth including leaf, stem, root, and whole-plant dry mass; dry/fresh mass ratio; stem length; and leaf DM/area. Of all the growth parameters reported, only the shoot/root dry mass ratio was not influenced significantly by the addition of blue light to the red LED radiation.

Extensive research has been conducted on the influence of light quality, particularly the ratio of red to far-red light (R : FR), on plant growth and photomorphogenesis (Sage, 1992; Smith, 1982). LEDs, with their narrow band width and easily manipulated mixture of wavelengths, are an excellent light source with which to conduct photobiological research. Of particular interest is the increase in stem elongation (Rajapaske et al. 1992, 1993; Smith, 1982) and stem dry mass (Hurd, 1974) of plants grown in reduced $\mathrm{R}$ : FR, such as might be found in shade. This response has been attributed to a reduced phytochrome photostationary state $(\phi)$. In these reports, the amount of blue light remained constant. In the present experiment, blue light levels varied and the resultant R : FR effect on stem growth was different. Plants grown under red LEDs with supplemental far-red radiation $(\mathrm{R}: \mathrm{FR}=5, \phi=0.84$, blue light $=0$ ) exhibit greater stem length and lower leaf/stem dry mass ratio than plants grown under $\mathrm{MH}$ lamps $(\mathrm{R}: \mathrm{FR}=3, \phi=0.82$, blue light $\left.=63 \mu \mathrm{mol} \cdot \mathrm{m}^{-2} \cdot \mathrm{s}^{-1}\right)$ and $660 / \mathrm{BF}(\mathrm{R}: \mathrm{FR}=103, \phi=0.88$, blue light $\left.=3 \mu \mathrm{mol} \cdot \mathrm{m}^{-2} \cdot \mathrm{s}^{-1}\right) \operatorname{or} 660(\mathrm{R}: \mathrm{FR}=148, \phi=0.88$, bluelight $=0)$. This suggests that small changes in blue light can result in changes in stem growth that do not fit the correlation of stem growth with $\phi$. Therefore, R : FR responses of plants must be taken in context with the absolute spectral output of the source in each wavelength range and not just the ratios of the spectral output within a limited wavelength range. Our results also agree with the suggestions of others (Bula et al., 1992; Rajapaske et al., 1992; Wheeler et al., 199 1) that blue light or the interaction of blue and other wavelengths are critical in determining photomorphogenic response.

\section{Literature Cited}

Barnes, C. and B. Bugbee. 1992. Morphological responses of wheat to blue light. J. Plant Physiol. 139:339-342.

Barnes, C., T.W. Tibbitts, J. Sager, G. Deitzer, D. Bubenheim, G. Koemer, and B. Bugbee. 1993. Accuracy of quantum sensors measuring yield photon flux and photosynthetic photon flux. HortScience 28: 11972000.

Barta, D.J., D.J. Tennessen, R.J. Bula, and T.W. Tibbitts. 1991. Wheat growth under a light emitting diode source with and without blue photon supplementation. ASGSB Bul. 5(1):51. (Abstr.)

Barta, D.J., T.W. Tibbitts, R.J Bula, and R.C. Morrow. 1992. Evaluation of light emitting diode characteristics for a space-based plant irradiation source. Adv. Space Res. 12(5):141-149.

Britz, S.J. and J.C. Sager. 1990. Photomorphogenesis and photoassimilation in soybean and sorghum grown under broad spectrum or blue-deficient light sources. Plant Physiol. 94:448-454.

Brown, C.S. and A.C. Schuerger. 1993. Growth of pepper, lettuce and cucumber under light emitting diodes. Plant Physiol. 102(1):88. (Abstr.)

Bula, R.J., R.C. Morrow, T.W. Tibbitts, D.J. Barta, R.W. Ignatius, and T.S. Martin. 1991. Light emitting diodes as a radiation source for plants. HortScience 26:203-205.

Hoenecke, M.E., R.J. Bula, and T.W. Tibbitts. 1992. Importance of 'blue' photon levels for lettuce seedlings grown under red-light-emitting diodes. HortScience 27:427-430.

Hurd, R.G. 1974. The effect of an incandescent supplement on the growth of tomato plants in low light. Ann. Bot: 38:613-623.

McCree, K.J. 1972. The action spectra, absorptance and quantum yield of photosynthesis in crop plants. Agr. Meteorol. 9:191-196.

McMahon, M.J., J.W. Kelly, D.R. Decoteau, R.E. Young, and R.K. Pollock. 1991. Growth of Dendranthema $\times$ grandiflorum (Ramat.) Kitamura under various spectral filters. J. Amer Soc. Hort. Sci. 116:950954.

Mortenson, L.M. and E. Stromme. 1987. Effects of light quality on some greenhouse crops. Sci. Hort. 33:27-36. 
Rajapaske, N.C., M.J. McMahon, and J.W. Kelly. 1993. End of day farred light reverses height reduction of chrysanthemum induced by $\mathrm{CuSO}$ spectral filters. Sci. Hort. 53:249-259.

Rajapaske, N.C., R.K. Pollock, M.J. McMahon, J.W. Kelly, and R.W. Young. 1992. Interpretation of light quality measurements and plant response in spectral filter research. HortScience 27:1208-1211.

Sage, L.C. 1992. Shade avoidance, p. 371-395. In L.C. Sage (ed.). Pigment of the imagination. Academic Press, London.

Sager, J.C., W.O. Smith , J.L. Edwards and K.L. Cyr. 1988. Photosynthetic efficiency and phytochrome photoequilibria determination using spectral data. Trans. Amer. Soc. Agr. Eng. 31(6):1882-1889.

Schuerger, AC. and C.S. Brown. 1994. Spectral quality may be used to alter plant disease development in CELSS. Adv. Space Res. 14:395398.

Schuerger, A.C. and D.J. Mitchell. 1992. Effects of temperature, hydrogen ion concentration, humidity, and light quality on disease caused by Fusarium solani f.sp. phaseoli in mung bean. Can. J. Bot. 70:17981808.

Senger, H. 1984. Blue light effects in biological systems. Springer Verlag,
Berlin.

Smith, H. 1982. Light quality, photoperception, and plant strategy. Annu. Rev. Plant Physiol. 33:481-518.

Tennessen, D.J., E.L. Singsaas, and T.D. Sharkey. 1994. Light-emitting diodes as a light source for photosynthesis research. Photosynthesis Res. 39:85-92.

Tibbitts, T.W., D.C. Morgan, and I.J. Warrington. 1983. Growth of lettuce, spinach, mustard, and wheat under four combinations of high pressure sodium, metal halide, and tungsten halogen lamps at equal PPFD. J. Amer. Soc. Hort. Sci. 108:622-630.

Tripathy, B.C. and C.S. Brown. 1995. Root-shoot interaction in the greening of wheat seedlings grown under red light. Plant Physiol. 107:407-411.

Warrington, I.J., K.J. Mitchell, and G. Halligan. 1976. Comparison of plant growth under four different lamp combinations and various temperature and irradiance levels. Agr. Meteorol. 16:231-245.

Wheeler, R.M., C.L. Mackowiak, and J.C. Sager. 1991. Soybean stem growth under high-pressure sodium with supplemental blue lighting. Agron. J. 83(5):903-906. 